\title{
La comunicación que el sacrificio deja al descubierto: lo sagrado y la experiencia interior en Georges Bataille
}

\section{The communication that sacrifice reveals: The sacred and the inner experience in Georges Bataille}

\author{
JAIME ABAD MONTESINOS \\ Collège Guillaume Budé (Francia)
}

Recibido: 08/07/15 Aceptado: 13/10/15

\begin{abstract}
RESUMEN
Moviéndose por caminos siempre complejos, la obra de Georges Bataille perdura como una de las más originales del pensamiento francés del siglo XX, donde su influencia ha sido inmensa. El presente artículo quiere mostrar el importante rol que jugarán en su obra las nociones de lo sagrado y de experiencia interior. Dicha experiencia, elemento central para entender su concepción de la religión, representará para Bataille la puesta en tela de juicio de todo lo conocido, pero también la íntima comunicación, ajena al discurso racional, que se establece entre el mundo profano y el mundo sagrado.
\end{abstract}

PALABRAS CLAVE

SAGRADO, EXPERIENCIA INTERIOR, COMUNICACIÓN, SACRIFICIO, MUERTE.

\section{ABSTRACT}

The work of Georges Bataille, moving through complex paths, remains as one of the most original works of the twentieth-century French thought, where his influence has been immense. This article aims to show the important role that the notions of sacred and inner experience will play in his work. This experience, the central element for understanding his conception

(C) Contrastes. Revista Internacional de Filosofia, vol. XXI-N² (2016), pp. 7-25. ISSN: 1136-4076

Departamento de Filosofía, Universidad de Málaga, Facultad de Filosofía y Letras Campus de Teatinos, E-29071 Málaga (España) 
of religion, will represent to Bataille the putting into question all the known, but also the intimate communication, foreign to rational discourse, which is set between the profane and the sacred world.

KEYWORDS

SACRED, INNER EXPERIENCE, COMMUNICATION, SACRIFICE, DEATH.

La noche encierra la efervescencia en descomposición y la lucha devastadora de todas las fuerzas, la absoluta posibilidad de todo, el caos, la materia que no es una, sino que lo encierra todo precisamente en su aniquilación.1

\section{INTRODUCCIÓN}

En SU CONOCIDA OBRA LAS FORMAS ELEMENTALES DE LA VIDA RELIGIOSA, destacaba Durkheim como un rasgo común a toda creencia religiosa la división del mundo en dos géneros opuestos: lo sagrado y lo profano, dos categorías humanas completamente separadas, entre las cuales se halla «una especie de vacío lógico» $\rangle^{2}$ que impide toda conexión fortuita entre ellas. Como apunta el sociólogo francés, la separación entre ambos mundos está marcada por la prohibición de lo profano de entrar en contacto impunemente con lo sagrado. Sin embargo, dicha prohibición no puede tener nunca un carácter absoluto, puesto que de esta forma se impediría toda posibilidad de comunicación entre ambos, y sin dicha comunicación lo sagrado no tendría razón de ser. Entre las dos categorías hay pues una estrecha relación que no oculta su esencial complejidad, y que nos hundirá en la esencia misma del pensamiento de Bataille: la comunicación que se establece entre estos dos ámbitos de la vida humana y que permite a un hombre entrar en relación con el mundo sagrado.

El conjunto de los escritos Bataille puede ser considerado como el intento de pensar y de experimentar ese vacío señalado por Durkheim. A lo largo de sus páginas va a desplazarse Bataille por ese espacio que se abre entre lo sagrado y lo profano, y que se expresa en términos de una experiencia al límite de lo

1 G. W. F. Hegel, Filosofía Real, tr. y ed. de J. M. Ripalda, Madrid: Fondo de Cultura Económica, 2006, p. 71.

2 E. Durkheim, Las Formas elementales de la vida religiosa, tr. A. M. Arancón, Madrid: Alianza Editorial, 2003, p. 80. 
posible. Lo sagrado es para Bataille el instante donde el individuo rompe su caparazón y logra salir de su aislamiento, donde se pone a sí mismo en cuestión y se abisma en un sentimiento de continuidad con el mundo inmanente. «Lo sagrado es comparable precisamente a la llama que destruye el bosque al consumirlo», ${ }^{3}$ escribirá Bataille. Como un fuego que calienta al hombre pero también le asusta, lo sagrado produce en nosotros un sentimiento esencialmente ambiguo, mezcla de pavor y de fascinación, que pone de manifiesto una experiencia que trasciende todo límite. El objetivo de estas páginas será tratar de dar cuenta de la importancia de lo sagrado en la obra de Bataille, y mostrar la centralidad de la noción de experiencia interior como vínculo de comunicación entre el espacio de lo sagrado y el de lo profano.

\section{Bataille y el Collège de Sociologie}

En julio de 1937 aparece publicado en la revista Acéphale un breve documento titulado: Déclaration sur la fondation d'un Collège de Sociologie, firmado, entre otros, por Georges Bataille, Roger Caillois o Pierre Klossowski, y que será, como el propio título indica, el texto fundacional del Collège de Sociologie. Las sesiones de dicho grupo comenzarán en otoño, prolongándose durante dos años, y en ellas participarán, además de los ya mencionados, autores como Alexandre Kojève o Michel Leiris. Como ha señalado Denis Hollier, ${ }^{4}$ el Collège de Sociologie será el último de los grupos de vanguardia surgidos en el período de entreguerras. No obstante, lejos de ser un mero movimiento estético, el Collège pretende constituirse como una suerte de «comunidad moral $\gg,{ }^{5}$ cuyo eje fundamental no será el arte o la literatura, sino la ciencia, principalmente psicología y sociología, proponiéndose como objetivo dar cuenta de las estructuras sociales en toda su complejidad. Profundamente marcado por las tensiones socio-políticas de su época, el Collège tratará de arrojar un poco de luz sobre la «actividad total del ser», ${ }^{6}$ no limitándose a las dimensiones racionales del ser humano, sino atendiendo especialmente a aquellas regiones secretas, reveladoras de una experiencia profunda, íntima, pero que trae consigo un instante de unidad comunal inexpresable. Ahora bien, la manifestación socio-cultural esencialmente creadora de unidad en una sociedad será, para el Collège de Sociologie y para el propio Bataille, lo sagrado. Tal y como él expone en la sesión inaugural del Collège: «lo sagrado era exacta-

3 G. Bataille, Théorie de la religion. Paris: Gallimard.2011, p. 71.

4 D. Hollier [ed.], Le Collège de Sociologie. 1937-1939. Paris: Gallimard, 1995, p. 14.

5 G. Bataille et al, «Déclaration sur la foundation d'un Collège de Sociologie», en D. Hollier [ed.]. Le Collège de Sociologie, op. cit., p. 27.

6 R. Caillois, G. Bataille y M. Leiris, «Pour un Collège de Sociologie», en D. Hollier [ed.], Le Collège de Sociologie, op. cit., p. 300. 
mente para mí el hecho específico del movimiento comunal de la sociedad».? El proyecto sociológico del Collège se define entonces como una sociología sagrada, destinada al estudio de todas aquellas manifestaciones sociales donde lo sagrado hace acto de presencia, proponiéndose con ello, según se expone en la Déclaration, «establecer los puntos de coincidencia entre las tendencias obsesionantes fundamentales de la psicología individual y las estructuras directrices que presiden la organización social y gobiernan sus revoluciones». ${ }^{8}$

En la sesión inaugural, dirigida por Bataille y Caillois, se afirma lo siguiente:

La sociología sagrada puede ser considerada como el estudio, no solamente de las instituciones religiosas, sino también del conjunto del movimiento comunal de la sociedad: es por esto que ella contempla como su objeto propio, entre otros, el poder y el ejército, y que considera todas las actividades humanas - ciencias, artes y técnicas - en tanto que ellas tienen un valor de comunión en el sentido activo del término, es decir, en tanto que ellas son creadoras de unidad.9

El camino que queda perfilado ya desde los comienzos de este grupo nos aleja entonces de las posiciones dominantes del pensamiento político contemporáneo, que considera la sociedad como una conjunto de individuos aislados, vinculados únicamente por un contrato social. Bataille será muy claro al respecto en su crítica a esta concepción surgida con la modernidad:

[La sociología sagrada] admite que existe además de los individuos que componen la sociedad, un movimiento de conjunto que transforma la naturaleza de ésta. Ella se separa pues de toda concepción según la cual la existencia social no añadiría a los individuos sino contratos, es decir, las concepciones precisamente sobre las que reposa el conjunto de la cultura actual.10

Distanciándose pues de la concepción de la sociedad propia de las democracias liberales, que la conciben como libre asociación de individuos guiados por intereses racionales, la sociología sagrada la contempla como un conjunto unitario aunque heterogéneo. La sociedad es entendida como un todo atravesado por movimientos centrífugos de unidad, que unen individuos en torno a

7 G. Bataille y R. Caillois, «La sociologie sacrée et les rapports entre "société", "organisme" et "être"», en D. Hollier [ed.]. Le Collège de Sociologie, op. cit., p. 36.

8 G. Bataille et al, «Déclaration sur la foundation d'un Collège de Sociologie», en D. Hollier [ed.]. Le Collège de Sociologie, op. cit., p. 27.

9 G. Bataille y R. Caillois, «La sociologie sacrée et les rapports entre "société", "organisme" et "être"», en D. Hollier [ed.]. Le Collège de Sociologie, op. cit., p. 36.

10 Idem. 
un punto en común, un núcleo sagrado originario que permanece como centro de la vida social.

No obstante, este elemento compartido no será un espacio físico sino un conjunto él mismo: un todo formado por objetos, creencias, prácticas, ritos, etc. Él es el lugar de horror y fascinación que se expresa en términos sagrados como lo desconocido. Lo sagrado se presenta como un tabú cultural situado en una región exterior al individuo, que vincula colectividades en torno suyo infundiendo respeto y adoración. El fenómeno de lo sagrado es vínculo social, pero también -y esto será esencial en la obra de Bataille- lugar de verdadera y profunda comunicación, que no puede reducirse a discurso racional. Incidir sobre el espacio de lo sagrado, objetivo del Collège de Sociologie, supone pues dar la vuelta al pensamiento hegemónico occidental que sostiene como origen de las sociedades el libre contrato desarrollado por sus miembros, para poner de manifiesto el poder originario de lo sagrado como fuente de cohesión social. Son las fuerzas religiosas el núcleo último en torno al cual se sientan los individuos y se forman las comunidades, no la razón política que organiza sociedades en función de intereses prácticos. Tratar de recuperar ese espacio caracterizado como sagrado, que oculta una dimensión más profunda de la realidad desdeñada por el pensamiento moderno, es el proyecto del Collège de Sociologie, pero también de la obra misma de Bataille. Sin embargo, dar cuenta de dicho espacio exigirá dirigir la mirada hacia experiencias ubicadas en el límite de la posible y ante las que la ciencia queda enmudecida, revelándose como instantes marcados por un desgarramiento que trascenderán necesariamente los límites iniciales del Collège. Los escritos posteriores de Bataille se convertirán entonces en reflejo de esa búsqueda personal que irá desmarcándose de toda ciencia objetiva, reflejo de un caminar imposible que adoptará en ocasiones tintes místicos.

\section{LA INTIMIDAD QUE NOS ES AJENA}

Afirmaba Bataille en El Erotismo que «somos seres discontinuos», ${ }^{11}$ individuos aislados arrojados a un mundo que se nos presenta como un enigma sin respuesta; sentimos nuestro entorno como un afuera donde el descanso es imposible, marcados de por vida por «la nostalgia de la continuidad perdida». ${ }^{12}$ Maurice Blanchot, con quien Bataille mantendrá una profunda amistad a lo largo de su vida, escribirá: «allí donde estoy solo el día ya no es más que la pérdida de la morada, la intimidad con el afuera sin lugar y sin reposo». ${ }^{13} \mathrm{El}$ mundo se nos ha hecho extraño porque hemos perdido la vinculación profunda con él, ya

11 G. Bataille, L'Érotisme. Paris: Éditions de Minuit., 2011, p. 15.

12 Ibid., p. 17.

13 M. Blanchot, L'espace littéraire. Paris: Gallimard. 1968, p. 24 
no es nuestro hogar sino tierra ajena. Nuestra relación con él se ve mediatizada por nuestra conciencia y por la presencia del trabajo, gracias al cual el hombre recrea el mundo y lo transforma, pero lo transforma como mundo humano, un mundo profano hecho a la medida de sí mismo y compuesto por objetos cuya esencia es ser simplemente útiles para el hombre. En cambio, para Bataille esta forma de ser en el mundo característica del hombre se contrapone a la del animal, dado que «todo animal está en el mundo como el agua en el interior del agua», ${ }^{14}$ es decir, no como elemento desligado del mundo y enfrentado a él, sino como parte indisoluble de su intimidad. No obstante, éste ya no es el destino del ser humano, porque él está condenado a experimentar la pérdida de la continuidad con el mundo circundante, a sentirlo como exterioridad para su conciencia. El hombre es para Bataille negatividad, porque su ser es acción transformadora del mundo, «está presente en el seno de esa Naturaleza como una noche en la luz, como una intimidad en la exterioridad de esas cosas que son en sì». ${ }^{15}$ En este punto es evidente la influencia del pensamiento hegeliano, tal y como fue expuesto por Alexandre Kojève, en sus conocidos cursos sobre la Fenomenología del Espíritu, y de los que Bataille será oyente asiduo. Respecto del ser humano escribe Kojève:

Él es Negatividad encarnada [...]. No es sino comprendiendo al Hombre como Negatividad como se le comprende en sus especificidad humana «milagrosa» haciendo de él un Yo que piensa y que habla, o que «separa» la esencia de su «conexión» natural o dada con la existencia. Sabemos, por otra parte, que, en un plano ontológico, la Negatividad se actualiza en tanto que Acto negador o creador.16

La negatividad se manifiesta, según Kojève, como acción negadora del mundo dado, es decir, como trabajo. Ahora bien, para Bataille, el trabajo, convertido en centro de la vida humana moderna, deja inevitablemente fuera de sí parcelas de la vida que no pueden reducirse a mera actividad planificada, parcelas que ponen en juego elementos que se sitúan más allá de concepciones utilitaristas. El mundo objetivo es un mundo desarrollado en función de la utilidad, donde el hombre mismo ha devenido objeto, es decir, parte de un proceso productivo, y la necesidad de producir y conservar los bienes prohíbe todo gasto desmedido, racionalizando el uso de los recursos disponibles en función del interés práctico. La producción industrial contemporánea es la

14 G. Bataille, Théorie de la religion, op. cit., 2011, p. 25.

15 G. Bataille, «Hegel, la muerte y el sacrificio», en Escritos sobre Hegel, tr. I. Herrera. Madrid: Arena Libros, 2005, p. 13.

16 A. Kojève, Introduction à la lecture de Hegel. Paris: Gallimard, 2008, p. 547. 
«base de la homogeneidad social», ${ }^{17}$ en ella cada elemento se relaciona con el resto en función de su utilidad, quedando excluido lo inútil para el desarrollo productivo, condicionado éste, en último término, por el aumento del beneficio.

Ahora bien, es preciso destacar que los elementos considerados inútiles para la actividad productiva no son excluidos del conjunto de la sociedad, sino únicamente de su parte homogénea, es decir, profana y productiva. Tales elementos no reductibles a mera utilidad práctica componen un espacio de exclusión donde se reúnen, para Bataille, las fuerzas heterogéneas de la existencia social. Ellas son los elementos considerados sagrados e inconmensurables, que la sociedad homogénea ha apartado porque no contribuyen a la estabilidad social. Sin embargo, este mundo heterogéneo no sólo estaría compuesto sólo por elementos sagrados en sentido estricto, sino por todo aquello que la sociedad homogénea ha expulsado de su seno. Lo heterogéneo es pues el conjunto de elementos que se resisten a la integración en la rutina de la vida cotidiana, es decir:

Los productos excretados por el cuerpo humano y ciertas materias análogas (basuras, gusanos, etc.); las partes de cuerpo, las personas, las palabras o los actos que tienen un valor erótico sugerente; los diversos procesos inconscientes tales como los sueños o las neurosis; los numerosos elementos o formas sociales que la parte homogénea es incapaz de similar: las muchedumbres, las clases guerras, aristocráticas y miserables, los diferentes tipos de individuos violentos o que al menos rechazan la norma (locos, agitadores, poetas, etc.).18

Todo ello hace patente el marcado carácter ambivalente de los elementos sagrados, poniendo de manifiesto la dificultad para dar cuenta de ellos en una definición estrecha. Por una parte, como se ha destacado anteriormente, son elementos de integración y cohesión social de la conciencia colectiva. Los ritos y prácticas son elementos esenciales para una sociedad, dado su importante rol en la forja de un sentimiento de unidad comunal. Pero, al mismo tiempo, están poseídos de una fuerza peligrosa que los separa del mundo profano, relegándolos a un espacio heterogéneo, que provoca en el sujeto reacciones afectivas de diferentes intensidad: «una veces hay atracción, otras repulsión, y todo objeto de repulsión puede convertirse en ciertas circunstancias en objeto de atracción o viceversa». ${ }^{19}$ Los elementos sagrados compondrían un espacio de heterogeneidad que el ser humano difícilmente puede asimilar, ellos marcan un punto de ruptura con lo profano que, lejos de tener siempre un efecto benéfico para el hombre, puede adoptar en ocasiones rasgos aterradores. Porque lo sagrado

17 G. Bataille, «La structure psychologique du fascisme», en Oeuvres complètes Vol. I. Paris: Gallimard, 1970 p. 340

18 Ibid., p. 346.

19 Ibid., p. 347. 
es, para Bataille, una realidad que despierta en nosotros un sentimiento contradictorio irresoluble, su esencia misma es permanecer en la contradicción entre dos polos. Sostiene Bataille en El Erotismo lo siguiente:

Fundamentalmente, es sagrado aquello que es objeto de una prohibición. La prohibición, designando negativamente la cosa sagrada, no tiene solamente el poder de producirnos - en el plano de la religión - un sentimiento de pavor y de temblor. En última instancia, este sentimiento se transforma en devoción; se convierte en adoración. Los dioses, que encarnan lo sagrado, hacen temblar a quienes los veneran, pero ellos los veneran igualmente. Los hombres están sometidos al mismo tiempo a dos movimientos: uno de terror, que produce rechazo, y otro de atracción, que controla un respeto fascinado. 20

Esta tensión entre dos realidades contrapuestas, la adoración y el terror, pone de manifiesto el carácter esencialmente ambiguo de lo sagrado, que se refleja en el sentimiento religioso que despierta en nosotros.

El movimiento dialéctico que opera en la esencia misma de lo sagrado, disociando la realidad religiosa en dos espacios netamente separados, lo puro y lo impuro, que no pueden concebirse sino estrechamente ligados, ha sido destacado por Roger Caillois (1989) o por el propio Durkheim (2003). En una conferencia que Caillois dará en el Collège de Sociologie con el título «La ambigüedad de lo sagrado» dirá:

En el fondo lo sagrado suscita en el fiel exactamente los mismos sentimientos que el fuego en el niño: mismo temor de quemarse con él, mismo deseo de encenderlo; misma emoción ante la cosa prohibida, misma creencia que su conquista aportará fuerza y prestigio - o herida y muerte en caso de fracaso. Y como el fuego produce a la vez el mal y el bien, lo sagrado desarrolla una acción afortunada o nefasta y recibe las calificaciones opuestas de puro y de impuro, de santo y de sacrílego que definen con sus límites propios las fronteras mismas de la extensión del mundo religioso.21

Sin embargo, siendo los elementos que componen el mundo heterogéneo los instantes donde el orden homogéneo del mundo se desgarra y queda puesto en cuestión, un determinado fenómeno prima para Bataille por encima de todos ellos. Dicho elemento, que viene inevitablemente a destruir el edificio racional de la parte homogénea de la sociedad, no es sino el fenómeno de la muerte. Ella concentra la fuerza de la contradicción que reduce a nada el orden del

20 G. Bataille, L'Érotisme, op. cit., pp. $71-72$.

21 R. Caillois, «L'ambiguïté du sacré», en D. Hollier [ed.], Le Collège de Sociologie, op. cit., p. 372. 
mundo creado por el hombre, destruye todo proyecto, abisma todo cálculo. Es el poder sagrado que el hombre se niega en ocasiones a aceptar pero que, sin embargo, llega por un instante con una violencia destructora ante la que no hay escapatoria. La muerte, al igual que lo sagrado, «es esencialmente aque1lo que, aunque imposible, está sin embargo ahí». ${ }^{22}$ Ahora bien, su esencia no es únicamente negadora. La muerte niega el orden producido por hombre, pero abre el mundo a la noche, ella desvela, para Bataille, la parte maldita. El trabajo humano reduce el mundo a mundo profano, pero deja de lado la noche de lo sagrado donde habita lo desconocido, y que nunca podrá ser descifrada bajo una mirada condicionada por el utilitarismo. El espacio de lo sagrado únicamente puede ser revelado en los actos violentos que desgarran la homogeneidad social: la violencia desmedida, el sueño, el delirio, la fiesta sagrada, la muerte. Todas ellas son experiencias límites que socavan el orden del mundo de las cosas, puesto que lejos de verse dominadas por una mentalidad pragmática, desencadenan una suma de fuerzas que gasta energías desmedidas. Ahora bien, tales experiencias serán igualmente condición necesaria para la regeneración del mundo. El fuego sagrado, que aterra al hombre y le fascina al mismo tiempo, purifica lo profano, devora con sus llamas los desechos del mundo homogéneo, pero los devuelve a la vida primigenia, a la continuidad intima donde el utilitarismo no tiene cabida, dejando así abierto el camino para el crecimiento de nuevas fuerzas.

Este espacio más allá de la planificación estratégica es la región de la continuidad del ser para Bataille, el dominio del que sólo la religión puede dar cuenta, y en el que la muerte tendrá un rol preponderante. En el curso de una fiesta sagrada la muerte hace acto de presencia como sacrificio, mediante el cual un objeto del mundo profano es extraído de él y enviado al espacio de lo sagrado. La muerte que lo aniquila lo devuelve así a la continuidad perdida. La concepción de la religión que Bataille propone se expresa pues como efervescencia destructora, como puro gasto desmedido, aterrador y fascinante al mismo tiempo. Su ser es una noche portadora de claridad que la modernidad ha desterrado porque es incapaz de dar cuenta de ella.

El Collège de Sociologie había defendido en todo momento su compromiso con una ciencia de lo social, así se nos expone ya desde la sesión inaugural: «la tentativa del Collège de Sociologie debe estar situada exclusivamente sobre el plano de la objetividad científica», ${ }^{23}$ y por ello no es de extrañar que tome como referencia a figuras como Durkheim, Mauss o Freud. Ahora bien, tratar de adentrarse por caminos que se desplazan al límite de lo posible, como pre-

22 G. Bataille, La souveraineté. Paris: Nouvelles Editions Lignes, 2012, p. 34.

23 G. Bataille y R. Caillois, «La sociologie sacrée et les rapports entre "société", “organisme" et "être"», en D. Hollier [ed.]. Le Collège de Sociologie, op. cit., p. 54. 
tenderá hacer Bataille, supone asumir las limitaciones de la ciencia, la tensión irreconciliable entre la razón y el vacío de la razón, donde ninguna sociología de la religión alcanza. En su obra Teoría de la religión nos da Bataille una caracterización de la esencia misma de su concepto de religión: ella es «la búsqueda de la intimidad perdida», ${ }^{24}$ es decir, esa intimidad que se le presenta al hombre primitivo atravesada de misterio y de terror, esa intimidad que el hombre fue relegando al olvido, avasallado por un mundo de objetos y por una racionalidad instrumental, y que no puede ser expresada en términos científicos, sino que habla con voz sagrada. «La realidad heterogénea es la de la fuerza o el choque», ${ }^{25}$ escribe Bataille, sin embargo la estructura del conocimiento científico precisa de una realidad neutra, compuesta de elementos mensurables. El espacio de la ciencia es pues el de la realidad homogénea, y nunca podrá dar cuenta de la inconmensurabilidad de fuerzas heterogéneas que tienen lugar en el ámbito de lo sagrado. Son pues evidentes los puntos de fricción entre las posiciones iniciales del Collège de Sociologie y el proyecto que va tomando forma en la mente de Bataille. ${ }^{26}$ Él mismo es consciente de ello cuando unos años después, en plena Segunda Guerra Mundial, escribe: «me irrito al pensar en el tiempo de «actividad» que pasaba -durante los últimos años de paz- esforzándome por llegar a mis semejantes. Tuve que pagar ese precio».27

El proyecto del Collège de Sociologie se revela entonces para Bataille esencialmente paradójico, porque en el momento de su máximo desarrollo choca con su propia limitación, da con la imposibilidad inherente a su proyecto: hablar de aquello de lo que, por naturaleza, no se puede hablar. Lo sagrado es esencialmente, según Bataille, comunicación, apertura, pero una comunica-

24 G. Bataille, Théorie de la religion, op. cit., p. 77.

25 G. Bataille, «La structure psychologique du fascisme», en Oeuvres complètes Vol. I, op. cit., p. 347.

26 El Collège, y su proyecto de crear una suerte de comunidad moral «ligada precisamente al carácter virulento del domino estudiado» (Bataille et al., «Déclaration sur la foundation d'un Collège de Sociologie», en D. Hollier [ed.], Le Collège de Sociologie, op. cit., p. 27), es decir: lo sagrado; parecía inevitablemente condenado ha disolverse dadas las diferentes formas de entender dicho concepto que tenían sus miembros. La última de las exposiciones es, en palabras de Bataille, «la expresión de un desacuerdo profundo que ha abierto ya una grieta en el edificio» (Bataille, Caillois y Leiris, «Le Collège de Sociologie», en D. Hollier [ed.]. Le Collège de Sociologie, op. cit., p. 799). Si filósofos como Kojève o Wahl, asistentes a algunas de las sesiones, no se sentían próximos a las tesis del Collège, más importantes resultarán las diferencias entre Bataille, Caillois y Leiris. Éste último en una carta a Bataille, le reprochará haberse apartado del ámbito de la sociología, tal y como fue desarrollada por Durkheim o Mauss, a pesar de reclamar su magisterio. Además de graves desviaciones de las reglas del método sociológico, el Collège de Sociologie sería responsable, según Leiris (cit. D. Hollier [ed.], Le Collège de Sociologie, op. cit., p. 820), de «resucitar simplemente las peores formas de capillas literarias».

27 G. Bataille, L'expérience intérieure. Paris: Gallimard, 2009, p. 109. 
ción más profunda y originaria de lo que toda comunicación lógica es capaz de articular. No se puede hablar de la religión desde su exterior como hace la ciencia, el proyecto de Bataille exige pues tratar la religión, «no como el profesor que hace historia de ella, que habla, entre otros, del brahman, sino como el brahman mismo». ${ }^{28}$ Estamos hablando pues de una «religión del interior». ${ }^{29}$ El lenguaje discursivo toma conciencia de su propia limitación, da con su inoperancia en el vacío que se abre entre lo sagrado y lo profano, siendo incapaz de dar cuenta de la comunicación profunda que lo sagrado desarrolla, porque «la comunicación profunda quiere el silencio», ${ }^{30}$ y ella se da en los momentos donde el lenguaje se abisma, donde el sujeto se sitúa entre la vida y la muerte.

Así pues, adentrarse en el vacío que comunica con lo sagrado implica llevar a cabo una meditación en solitario, el propio Bataille señala que al desmarcarse de la actividades colectivas previas a la guerra, sumergiéndose en la reflexión personal, su pensamiento «alcanza la madurez». ${ }^{31}$ Partiendo del aspecto de construcción colectiva que tiene lo sagrado, en tanto que instante de unidad comunal, esta nueva etapa del pensamiento de Bataille va a tratar de hundirse en la esencia misma de aquel, como «efervescencia prodiga de la vida» ${ }^{32}$ : movimiento dialéctico de fuerzas que se encadenan y desencadenan de forma violenta y cuya culminación es el desgarramiento del sujeto.

\section{EL CAMINO DE LA EXPERIENCIA INTERIOR}

La madurez del pensamiento de Bataille, que se inicia con su obra La experiencia interior, deja al descubierto un camino más personal, en el que van a confluir elementos dispares, pero que guarda una profunda continuidad a través de sus páginas: el radical esfuerzo por quebrar «la soberanía del sujeto filosofante». ${ }^{33} \mathrm{Al}$ sumergirse en profundas vivencias interiores, los escritos de Bataille ponen de manifiesto una reelaboración de la figura del sujeto, desplazada a los espacios donde éste se enfrenta a tinieblas que socavan todo cuanto había creído hasta entonces. Como el mismo dirá, «el objeto de mi búsqueda no puede ser distinguido del sujeto mismo, pero debo ser más preciso: del sujeto en su punto de ebullición». ${ }^{34}$ Este punto límite de la subjetividad, donde un hombre da con su propia finitud y queda ante él lo desconocido, es una experiencia que transciende todo lo posible, y que Bataille caracterizará como interior. Ella es

28 G. Bataille, L'Érotisme, op. cit., p. 37.

29 Ibid., p. 36.

30 G. Bataille, L'expérience intérieure, op. cit., p. 109.

31 Ibid., p. 110.

32 G. Bataille, Théorie de la religion, op. cit., p. 71.

33 M. Foucault, «Prefacio a la transgresión», en De lenguaje y literatura, tr. I. Herrera Baquero. Barcelona: Paidós. 1996, p. 134.

34 G. Bataille, La Parte Maudite. Paris: Éditions de Minuit, 2011, p. 42. 
la vivencia íntima que adopta rasgos imposibles y que, sin amedrentarse ante la muerte, nos permite entrar en contacto con lo sagrado. Porque el límite de la muerte -el punto de mayor desgarramiento del sujeto- es el instante soberano donde se abre la comunicación intima con los otros y con el mundo. Como ya había expuesto Hegel la muerte «es lo más terrible», ${ }^{35}$ pero la vida del espíritu no se aterra en absoluto ante ella, puesto que únicamente permaneciendo frente al desgarramiento que la muerte representa, el espíritu da con su verdad. ${ }^{36}$

El camino del espíritu que desemboca en lo profundo lo sitúa cara a cara con la muerte, pero allí mismo él da con su fuerza esencial al demorarse ante el vacío. Ese instante de demora ante el abismo representa para Bataille la experiencia interior de un sujeto que se siente «llevado "a la altura de la muerte"», ${ }^{37}$ un vértigo condenado a hundirse en el silencio, "donde el yo no importa nada»..$^{38}$ La muerte es un elemento central para entender el rol de lo sagrado en el pensamiento de Bataille. El sacrificio representa la fuerza destructora que consagra la unidad comunal: «es al arruinar en mí mismo, en otro, la integridad del ser, que yo me abro a la comunión», ${ }^{39}$ porque más allá de un mero crimen es una actitud de entrega, la de un objeto profano que se convierte en don entregado al mundo de lo sagrado. El sacrificio será pues una experiencia límite que desgarra y disuelve al sujeto, pero al mismo tiempo lo abre a la intima comunión con el mundo, es pues esencialmente comunicación con lo sagrado.

Siendo la religión para Bataille una búsqueda imposible por entrar en contacto con lo sagrado, el sacrificio es el medio del que ella se sirve para devolver al mundo sagrado lo que la utilidad ha convertido en profano. El sacrificio destruye el objeto y lo borra del mundo profano, pero al destruirlo lo sacraliza, y lo hace parte del mundo de los dioses. La fiesta sagrada, que

35 G. W. F. Hegel, Fenomenología del espíritu, tr. M. Jiménez Redondo. Valencia: PreTextos, 2009 p. 136

36 La referencia de Hegel sobre la muerte aparece en el Prólogo de la Fenomenología del Espíritu, según Denis Hollier ésta es una de las «citas preferidas» de Bataille (D. Hollier [ed.]. Le Collège de Sociologie, op. cit., p. 731). No en vano él la considerará un texto esencial, no sólo para entender a Hegel, «sino en todos los sentidos» (G. Bataille, «Hegel, la muerte y el sacrificio», en Escritos sobre Hegel, op. cit, p. 16). Ahora bien, dicha consideración se sustenta en la interpretación de Kojève de la filosofía hegeliana, que sitúa a la muerte, es decir, a la toma de conciencia de la finitud del hombre, como manifestación esencial de su libertad individual y condición de todo desarrollo histórico, hasta el punto de interpretar el pensamiento hegeliano como «una filosofía de la muerte» (A. Kojève, Introduction à la lecture de Hegel, op. cit., p. 539) y al ser humano como «la muerte que vive una vida humana» (Ibid., p. 550).

37 G. Bataille, «La joie devant la mort», en D. Hollier [ed.]. Le Collège de Sociologie, op. cit., pp. 739-740.

38 G. Bataille, L'expérience intérieure, op. cit., 2009, p. 64.

39 G. Bataille, Discussion sur le péché. Paris: Nouvelles Éditions Lignes. 2010, p. 65. 
culmina en un sacrificio, será pues el instante comunal donde son transgredidos los límites de lo profano, y permitirá superar el vacío lógico que según Durkheim separa al mundo profano del mundo sagrado. Allí donde la vida se entrega y se consume se desvela la senda de la verdadera comunicación: aquella que íntimamente une a los seres que el mundo de las cosas mantiene separados, pero los une durante un instante, lo que dura el delirio del éxtasis y de la fiesta. Ahora bien, esta comunicación de la que habla Bataille tiene poco que ver con la comunicación lógica, ella no argumenta sino que pone todo en cuestión, deja al lenguaje al desnudo, puesto que reclama «unos seres que tienen en sí mismos al ser puesto en juego, situado en el límite de la muerte, de la nada». ${ }^{40}$ La consecuencia necesaria es que una comunicación de estas características no puede ser apresada por ningún discurso, exige una pérdida, y sin embargo es profundamente reveladora. Ella revela la vida en su plenitud, la continuidad profunda del mundo que traza un vínculo entre la vida y la muerte; pero supone al mismo tiempo un socavamiento del orden real dominado por la utilidad. El sacrificio impone una nueva comunicación cuya fuerza central es la figura de la muerte. Ella hunde al sujeto en el vacío, pero al desgarrarlo se constituye como vínculo profundo entre dos extremos: lo sagrado y lo profano. Sin embargo, como se ha visto, dicha fuerza está lejos de tener únicamente una presencia benéfica, el sujeto no puede ver en ella sino «la pureza de una exigencia $\sin$ esperanza», ${ }^{41}$ una pureza aterradora que no se deja apresar en las redes del lenguaje. La muerte es experiencia de lo imposible, de lo que nos negamos a creer y sin embargo se hace presente, como la cima moral que se mantiene siempre inalcanzable y sólo la fiesta trágica revela. ${ }^{42}$

Sin duda la obra de Bataille no puede entenderse sin tener en cuenta la estrecha, aunque compleja relación, que mantiene con el pensamiento místico, ahora bien, dista mucho de poder ser reducida a misticismo cristiano. ${ }^{43}$ Tal y como él expone:

40 Ibid., p. 57.

41 G. Bataille, L'expérience intérieure, op. cit., p. 86.

42 La noción de cima moral, de claras resonancias nietzscheanas, será el centro de una conferencia dada por Bataille en marzo de 1944, a la que seguirá una larga discusión sobre el pecado y entre cuyos asistentes se encontrarán Sartre, Camus, Klossowski, Leiris, Blanchot o Hyppolite, entre otros. La cima moral es para Bataille un lugar de purificación por el exceso, «un momento de puesta en juego» (G. Bataille, Discussion sur le péché, op. cit., p. 57), al que se accede tras un exuberante derroche de fuerzas. Ella es un lugar de comunicación sacrificial que se contrapone a la noción de caída, en la que se concentran los momentos de conservación del ser.

43 Lo expuesto en La experiencia interior llevará a Jean-Paul Sartre a calificar a Bataille como un nuevo místico. De él dirá: «Es realmente un místico quien habla, un místico que ha visto a Dios y que rechaza el lenguaje demasiado humano de los que no lo han visto» (J.-P. 
Entiendo por experiencia interior lo que habitualmente se llama experiencia mística: los estados de éxtasis, de fascinación, o al menos de emoción meditada.

$$
[\ldots]
$$

No me gustan tampoco las definiciones estrechas. La experiencia interior responde a la necesidad en que me hallo - y conmigo la existencia humana - de ponerlo todo en tela de juicio (en cuestión) sin reposo admisible.

$$
[\ldots]
$$

He querido que la experiencia condujese a donde ella llevase, no llevarla a algún fin dado de antemano. Y adelanto que no lleva a ningún puerto (sino a un lugar de extravío, de sin-sentido). He querido que el no-saber fuese su principio [...]. Pero esta experiencia nacida del no-saber permanece en él decididamente. No es inefable, no se le traiciona si se habla de ella, pero, a las preguntas del saber, ella hurta incluso al espíritu las respuestas que éste aún tenía. La experiencia no revela nada, y no puede ni fundar la creencia ni partir de ella.44

Diferenciaba Paul Valéry en uno de sus Cuadernos (Cahiers) dos géneros de filósofos: los explicativos y los críticos, ambos marcados por dos defectos esenciales $^{45}$. El defecto de los primeros es hacer uso de más de lo necesario, el de los segundos ocultarse bajo un aparente rigor lingüístico. No obstante, junto a ellos existiría, para Valéry, un tercer género minoritario, aquel filósofo «casi místico» que, tendiendo a sustituir la explicación por la identificación, «pretende sentir el mundo». Pero el mundo, según Bataille, no se le presenta al hombre como la manifestación del poder creador de Dios, sino, al contrario, como el «enigma a resolver». ${ }^{46}$ La verdad última del hombre es ser una «súplica sin respuesta», ${ }^{47}$ instalada en el vacío que únicamente la experiencia interior revela, porque ella descubre el orden intimo del mundo donde la subjetividad queda fracturada, diluida en la corriente de la vida inmanente. Los sistemas religiosos como el cristianismo son caracterizados por Bataille como «economías de la

Sartre, «Un nouveau mystique», en Situations I. París: Gallimard, 1947, p. 168). La experiencia interior adopta para Sartre una doble configuración: como Evangelio y como Invitación al Viaje, testimonio de una región desconocida, pero también experiencia de un «descenso» (Ibid., p. 140) que se hace presente como sacrificio de la palabra.

44 G. Bataille, L'expérience intérieure, op. cit., p. 15 - 16.

45 P. Valery, Cahiers. Volume I. Paris: Gallimard, 1973, p. 553.

46 G. Bataille, L'expérience intérieure, op. cit., p. 11.

47 Ibid., p. 25 
salvación» ${ }^{48}$ dado que proponen al hombre obtener la felicidad eterna en un mundo situado más allá del mundo que le rodea. Estrechamente ligada al modo de producción de las sociedades capitalistas, una vida que pone su vista en el más allá descarta necesariamente todo aquello que lo aleja de su objetivo, que no resulta útil a su proyecto. A las religiones de estas características Bataille contrapondrá el de una «economía del sacrificio» ${ }^{49}$ propia de los pueblos primitivos, donde los intercambios mercantiles se dan dentro del marco de una fiesta sagrada, que exige el gasto desmedido de una parte de la producción.

Los escritos de Bataille reflejan pues la puesta en cuestión de todo lo pensado, pero representan igualmente la toma de conciencia de que dar con una experiencia que nos permita sentir el mundo sólo puede llevarse a cabo allí donde éste se desgarra. Es en los espacios destinados al sacrificio donde damos con el ser íntimo del mundo, como a través de una herida abierta damos con la carne viva. Hablar de tal experiencia límite supone hablar en términos de una experiencia interior ajena a las leyes lógicas del discurso significante, pues su esencia pone de manifiesto la imposibilidad de una aproximación lingüística a la continuidad del ser. La hermenéutica contemporánea ha destacado el carácter eminentemente lingüístico de la experiencia humana del mundo, que atraviesa la historia de la metafísica desde sus orígenes. El lenguaje es, en palabras de Gadamer, «un centro en el que se reúnen el yo y el mundo, o mejor, en el que ambos aparecen en su unidad originaria». ${ }^{50} \mathrm{La}$ noción de experiencia interior propuesta por Bataille supondrá una clara puesta en cuestión de la lingüisticidad como elemento mediador. Si la relación entre el hombre y el mundo es lingüística, entonces es comprensible desde su origen. Sin embargo, la ruptura del discurso que opera la experiencia interior lleva al hombre hasta el límite de lo posible, desnuda al lenguaje y deja al descubierto, no el saber del mundo, sino el no-saber, que únicamente se alcanza por el camino del éxtasis.

La lectura antropológica de la filosofía hegeliana hecha por Kojève ha destacado la acción negadora del hombre, dado que ella destruye el mundo dado, pero lo recrea mediante el trabajo, y es al generar mundo como el hombre se realiza a sí mismo. La experiencia interior, no obstante, se revela como «lo contrario de la acción». ${ }^{51}$ Es lo contrario porque toda acción exige un cálculo de fuerzas, toda acción es proyecto que vincula el presente con un tiempo por venir, donde se aguarda obtener unos determinados resultados en función de los energías dispuestas. La experiencia interior nunca puede ser acción, porque su 240.

48 G. Bataille, «Le sacrifice», en Oeuvres complètes Vol. II. Paris: Gallimard, 1970, p.

49 Ibid., p. 241

50 H.-G. Gadamer, Verdad y Método I, tr. A. Agud Aparicio y R de Agapito. Salamanca: Sígueme, 2003, p. 567.

51 G. Bataille, L'expérience intérieure, op. cit., p. 59. 
esencia es la paradójica disolución de toda planificación, la destrucción de todo proyecto, de todo cálculo: ella es el instante presente donde el sujeto se abisma en la noche del no-saber. Emprender la senda de la ciencia y del conocimiento supone dar forma a un proyecto, a la búsqueda del saber que tiene la verdad por horizonte. Pero Bataille establece claramente una oposición directa entre el proyecto y la experiencia del sacrificio, ella es su propia verdad soberana:

Lo contrario del proyecto es el sacrificio. El sacrificio cae en las formas del proyecto pero solamente en apariencia (o en la medida de su decadencia) [...]. Y, mientras que en el proyecto sólo cuenta el resultado, es el acto mismo lo que, en el sacrificio, concentra en sí el valor. Nada en el sacrificio se aplaza para más tarde, tiene el poder de ponerlo todo en duda, en el instante en que tiene lugar, de determinarlo todo, de hacerlo todo presente. El instante crucial es el de la muerte, sin embargo, desde que la acción comienza todo está puesto en tela de juicio, todo está presente. 52

Bataille ha hablado de experiencia interior como experiencia próxima a lo místico, pero su concepción del acto sacrificial nos aleja inevitablemente de la serena contemplación de Dios, su ser es la pérdida instalada en el límite de toda experiencia posible, «es lo análogo de un suplicio». ${ }^{53} \mathrm{Si}$ la experiencia interior es el camino del éxtasis que une lo sagrado y lo profano, se revela entonces como un camino esencialmente desgarrador y contradictorio, porque todo camino por recorrer exige una gestión racional de las fuerzas disponibles, y la experiencia interior reclama un gasto desmedido de fuerzas ajeno a toda planificación. Ella es el proyecto de disolución de todo proyecto, «es el ser sin demora» ${ }^{54}$ que no planifica sino que derrocha sin límites. La experiencia interior es pues, en último término, la experiencia de una pérdida: la pérdida de uno mismo, es el instante revelador de la vida íntima que la sociedad del trabajo ha anulado. Al sujeto autónomo de la modernidad Bataille contrapone una subjetividad destinada a entregarse en sacrificio. Pero es precisamente esta actitud de entrega lo que revela su soberanía, al ser capaz de elevarse a la altura de la muerte para ponerlo todo en cuestión. No obstante, dicho acto sacrificial está necesariamente fuera del horizonte de sentido del pensamiento hegemónico, puesto que, al imponer el sacrificio un gasto desmedido, aniquila las fuerzas disponibles en lugar de preservarlas. El acto sacrificial abre una grieta en el orden del mundo de las cosas, pero al ponerse como no-ser de dicho orden desencadena una fuerza de comunicación secreta que revela, paradójicamente, el ser íntimo del mundo.

52 Ibid., p. 158

53 Ibid., p 45.

54 Ibid., p. 60.

Contrastes vol. XXI-N² (2016) 
Los escritos de Bataille reflejan el esfuerzo por dejar al descubierto la conexión que se opera entre el mundo sagrado y el mundo profano cuando todas la barreras son transgredidas, cuando el hombre «rompiendo la crisálida, tiene consciencia de desgarrarse a sí mismo». ${ }^{55}$ La experiencia interior desencadena una íntima comunicación del hombre con un mundo que escapa a todo discurso, que no es otro que el sagrado. Ella borra todas las barreras, trasciende todos los límites, y lleva a cabo la profunda identificación del sujeto y del objeto, la fusión de ambos que es su esencial desgarramiento, «siendo como sujeto el no-saber, como objeto lo desconocido». ${ }^{56}$ Ella es comunicación en el borde mismo entre la vida y la muerte. La experiencia interior de la que habla Bataille es, en definitiva, el sacrifico sagrado donde el sujeto se hunde en la noche durante un instante.

Sin embargo, no podemos evitar ser conscientes de que ignoramos todo sobre ese instante, únicamente poseemos el silencio de la noche, que es y será siempre lo desconocido. La crisis interna y la posterior disolución del Collège de Sociologie ponen de manifiesto la imposibilidad de desarrollar un discurso científico de lo que, por esencia, está fuera del alcance de la razón. Bataille es bien consciente de ello, tal y como expondrá en El Erotismo: «De todos modos, todo el mundo reconocerá que ni la filosofía ni las ciencias pueden concebir el problema que la aspiración religiosa ha planteado» ${ }^{57} \mathrm{El}$ discurso lógico da con su propio límite cuando ante él se abre el espacio de lo heterogéneo: el afuera de lo pensable que sólo la religión revela. No obstante, como han pretendido mostrar estas páginas, dicha región donde se instala lo heterogéneo es el lugar por donde Bataille escoge desplazarse, aunque ello suponga asumir la insuficiencia del lenguaje. Porque es el desgarramiento del sujeto, que nos aterra y nos fascina al mismo tiempo, el profundo contacto con el mundo del que nos sentimos ausentes. Esta es la esencia misma del sentimiento de lo sagrado que atraviesa la obra de Bataille, y que se expresa en términos de gasto, erotismo, fiesta, éxtasis. Es por el acto del sacrificio como el hombre atraviesa el vacío de la noche entre lo sagrado y lo profano. El sacrificio lleva en su ser la destrucción y la muerte, pues destruye el objeto como cosa profana, como elemento perteneciente al reino de la utilidad, pero lo devuelve al mundo sagrado, lo restituye en lo más profundo de la intimidad perdida y anhelada por el ser humano. Como ya hemos apuntado anteriormente, la religión es para Bataille esa búsqueda de continuidad con el mundo sagrado, ese deseo esencialmente desgarrado y destructor: «la religión es la puesta en cuestión de todas las cosas». ${ }^{58}$ Más allá

55 G. Bataille, L'Érotisme, op. cit., p. 42.

56 G. Bataille, L'expérience intérieure, op. cit., p. 21.

57 G. Bataille, L'Érotisme, op. cit., p. 37.

58 G. Bataille, Le Coupable. Paris: Gallimard, 2010, p. 122. 
de dogmatismos y ritos, la religión es un caminar angustiado atravesado por el silencio que trasciende toda comunidad, que peregrina en solitario, pero se convierte en comunicación sagrada con el orden íntimo del mundo. Es pues dicha búsqueda una búsqueda extática, y ningún lenguaje puede dar cuenta de ella. Tal y como destacará Bataille en La experiencia interior: «mi búsqueda tuvo en primer lugar un objeto doble: lo sagrado, y después el éxtasis» ${ }^{59}$ Condenada a vagar en la noche de lo imposible, dicha búsqueda no puede sino despertar en quien se atreve a emprenderla un sentimiento ambiguo, de terror y de fascinación: el sentimiento de lo sagrado.

\section{Conclusión}

El concepto de lo sagrado en Bataille es un término complejo que, como se ha visto, se resiste a una definición estrecha y atraviesa toda su obra. Íntimamente ligados en sus comienzos a los trabajos de sociólogos franceses como Durkheim y Mauss, los escritos de Bataille se inclinarán pronto hacia otros enfoques metodológicos a la hora de dar cuenta del fenómeno religioso. Su pensamiento, como ya destacó Foucault, «define el espacio de una experiencia en la que el sujeto que habla, en lugar de expresarse, se expone, va al encuentro de su propia finitud y bajo cada palabra se encuentra remitido a su propia muerte». ${ }^{60} \mathrm{Tal}$ experiencia es caracterizada por Bataille como una experiencia interior, aquella que transciende los límites de lo posible y se constituye, no como fundamento de saber, sino como pérdida de todo fundamento. La experiencia interior representa el cuestionamiento de todo cuanto el sujeto cree saber, ella es la fuerza que deja la subjetividad al desnudo. En el vacío que traza a su alrededor, dicha experiencia se convierte en la única autoridad, en el instante soberano donde el sujeto es devuelto a la intimidad profunda del mundo. Pero ello exige una actitud de entrega, la de la vida misma que se sitúa frente a frente con la muerte. La experiencia interior, elemento central para entender lo sagrado en Bataille, sólo se da en los momento límites donde el sujeto se desgarra: la fiesta, el éxtasis, el sacrificio... Ella, fascinante y aterradora al mismo tiempo, le abre al sujeto el mundo de lo sagrado, de la noche, de lo imposible.

59 G. Bataille, L'expérience intérieure, op. cit., p. 97.

60 M. Foucault, «Prefacio a la transgresión», en De lenguaje y literatura, op. cit., p. 142 
JAIME ABAD es español en el Lycée général et technologique François-Joseph Talma (Francia)

Líneas de investigación:

Filosofía francesa contemporánea.

Publicaciones:

«Guy Debord: el espectáculo, la mercancía y la inversión de la realidad». Cuaderno de Materiales. Revista de Filosofía. $\mathrm{N}^{\mathrm{o}}$ 24, 2012, pp. 5 - 25.

«El tiempo, la memoria y el compromiso. Chris Marker, un viaje através de las imágenes». Sesión no numerada: Revista de letras y ficción audiovisual, $\mathrm{N}^{\mathrm{o}} 3$, 2013, pp. 180-202 ISSN 2173-5123.

Correo electrónico: jaime-abad@hotmail.com 
